\title{
Metastasis of nasopharyngeal carcinoma to parotid lymph nodes: a retrospective study
}

\author{
Shengye Wang ${ }^{1,2+}$, Jianlin Lou $^{3 \dagger}$, Suzhan Zhang ${ }^{1+}$, Liang Guo ${ }^{3}$, Kejing Wang ${ }^{3}$ and Minghua Ge ${ }^{3 *}$
}

\begin{abstract}
Background: Malignant parotid tumors are rare metastases originating from nasopharyngeal carcinoma (NPC). This study aimed to investigate the clinicopathological features and outcome of patients with metastasis of NPC to parotid lymph nodes after surgical therapy.

Methods: We enrolled 14 NPC patients who had metastatic disease to parotid lymph nodes after IMRT. They received surgical treatment by total parotidectomy with neck dissection, superficial parotidectomy with neck dissection, partial parotidectomy with neck dissection, total parotidectomy, or superficial parotidectomy. Their age, gender, histopathology, clinical findings, and treatment outcome were analyzed.

Results: After radiotherapy, parotid metastasis represented as uncontrolled disease in three cases and as recurrent disease in 11 cases. All the 14 patients received salvaged surgery successfully. Pathologic findings showed grade 3 in most patients. The follow-up ranged from 11 to 120 months and the overall three- and five-year survival was 49.5\% and $37.1 \%$, respectively.

Conclusions: Metastasis to parotid lymph nodes should be examined in NPC patients after IMRT. Resection of the inferior parotid lymph nodes is recommended for patients with cervical metastasis, and superficial or total parotidectomy and adjuvant therapy are recommended for intraparotid lymph node metastasis.
\end{abstract}

Keywords: Parotid node metastasis, Nasopharyngeal carcinoma, Neck dissection

\section{Background}

A wide range of primary and metastatic neoplasms can present as masses in the parotid gland. Roughly a quarter of malignant parotid tumors are metastases originating from head and neck tumors such as scalp, face, eyelid, oral cavity, and oropharynx. Among malignant parotid tumors, squamous cell carcinoma (SCC) and malignant melanoma are the most common [1-3]. Nasopharyngeal carcinoma (NPC) has a high incidence in China, especially in the southeast.Malignant parotid tumors are rare metastases originating from NPC. Radiotherapy is the most standardized method for NPC and the conventional dose of radiotherapy is between 60 and 70 Gy.

The parotid space harbors three groups of lymph nodes determined by the embryological development of the parotid gland. The first group of lymph nodes are

\footnotetext{
* Correspondence: gemhdr@126.com

${ }^{\dagger}$ Equal contributors

${ }^{3}$ Department of Head and Neck Surgery, Zhejiang Cancer Hospital, 38\# Guangji Road, Hangzhou 310022, China

Full list of author information is available at the end of the article
}

embedded within the parotid fascia, the second group in the parotid parenchyma, and the last group such as the preauricular lymph nodes remain extrafascial and extraglandular. Although metastases to parotid lymph nodes are uncommon, it should always be considered in the differential diagnosis of a parotid mass. In this study we aimed to review and investigate the clinicopathological features and outcome of patients with metastasis of NPC to the parotid lymph nodes.

\section{Methods}

This study was conducted according to the Declaration of Helsinki on biomedical research involving human subjects. The study protocol was approved by Ethics Committee of Zhejiang Cancer Hospital. The approval number is zjzlyy [2014]-11-96. We retrospectively reviewed the records of patients with NPC in Zhejiang Cancer Hospital between January 2001 and December 2012. Among all 9,602 cases of NPC, 14 patients had metastasis of NPC to parotid lymph nodes after IMRT and received salvaged surgical 
therapy. In detail, all patients were asked to lie in the supine position and to wear a plastic head and neck mask. The primary tumor and whole neck were treated by IMRT. The total dose was 69 Gy in 30 fractions at 2.3 Gy/fraction to the primary gross target volume
(PGTV), 66 Gy to the positive nodal gross target volume (GTV) node, 63 Gy to the planning target volume (PTV) node, 60 Gy to the high-risk neck regions, and 54 Gy to the low-risk neck regions. PGTV included GTV of nasopharynx lesion and retropharyngeal lymph

Table 1 The clinical data on metastasis of nasopharyngeal carcinoma cancer to parotid lymph nodes

\begin{tabular}{|c|c|c|c|c|c|c|c|c|c|c|}
\hline Gender & Age & $\begin{array}{l}\text { Pathology } \\
\text { and grading }\end{array}$ & $\begin{array}{l}\text { Parotid } \\
\text { metastasis }\end{array}$ & $\begin{array}{l}\text { Treatment of } \\
\text { primary tumor }\end{array}$ & $\begin{array}{l}\text { Treatment of } \\
\text { metastasis }\end{array}$ & $\begin{array}{l}\text { Surgery } \\
\text { mode }\end{array}$ & $\begin{array}{l}\text { Parotid lymph } \\
\text { node metastasis }\end{array}$ & Size & $\begin{array}{l}\text { Facial nerve } \\
\text { paralysis }\end{array}$ & Outcome \\
\hline \multirow[t]{3}{*}{ Female } & \multirow[t]{3}{*}{45} & \multirow[t]{3}{*}{$\mathrm{SCC}, \mathrm{G} 3$} & \multirow[t]{3}{*}{ Uncontrolled } & \multirow[t]{3}{*}{ CRT } & \multirow[t]{3}{*}{$S$} & \multirow[t]{3}{*}{ SP } & \multirow[t]{3}{*}{ superficial } & \multirow[t]{3}{*}{$<3 \mathrm{~cm}$} & \multirow[t]{3}{*}{-} & M \\
\hline & & & & & & & & & & AWD \\
\hline & & & & & & & & & & 15 months \\
\hline \multirow[t]{2}{*}{ Male } & \multirow[t]{2}{*}{46} & \multirow[t]{2}{*}{ SCC, G3 } & \multirow{2}{*}{$\begin{array}{l}\text { Delayed } \\
15 \text { months }\end{array}$} & \multirow[t]{2}{*}{ RT } & \multirow[t]{2}{*}{$S$} & \multirow[t]{2}{*}{ SP } & \multirow[t]{2}{*}{ superficial } & \multirow[t]{2}{*}{$<3 \mathrm{~cm}$} & \multirow[t]{2}{*}{-} & ANED \\
\hline & & & & & & & & & & 97 months \\
\hline \multirow[t]{3}{*}{ Male } & \multirow[t]{3}{*}{44} & \multirow[t]{3}{*}{$\mathrm{SCC}, \mathrm{G} 3$} & \multirow{3}{*}{$\begin{array}{l}\text { Delayed } \\
47 \text { months }\end{array}$} & \multirow[t]{3}{*}{ CRT } & \multirow[t]{3}{*}{$S$} & TP & superficial & $>3 \mathrm{~cm}$ & - & M \\
\hline & & & & & & & & & & DOD \\
\hline & & & & & & & & & & 53 months \\
\hline Male & 74 & SCC, G3 & Delayed & CRT & S & $P P+N D$ & inferior & $<3 \mathrm{~cm}$ & - & DOD \\
\hline & & & & & & & & & & 24 months \\
\hline Female & 46 & SCC, G3 & Delayed & CRT & $S$ & $\mathrm{SP}+\mathrm{ND}$ & superficial & $>3 \mathrm{~cm}$ & + & ANED \\
\hline & & & 108 months & & & & & & & 17 months \\
\hline Male & 51 & SCC, G3 & Delayed & CRT & $S$ & $\mathrm{TP}+\mathrm{ND}$ & superficial & $<3 \mathrm{~cm}$ & + & DOD \\
\hline & & & 105 months & & & & deep & & & 28 months \\
\hline Male & 57 & SCC, G3 & Delayed 36 months & RT & $S+R T$ & TP & superficial & $>3 \mathrm{~cm}$ & + & $L R$ \\
\hline & & & & & & & & & & AWD \\
\hline & & & & & & & & & & 38 months \\
\hline Male & 32 & SCC, G3 & Uncontrolled & CRT & $S+R T$ & $P P+N D$ & inferior & $>3 \mathrm{~cm}$ & - & M \\
\hline & & & & & & & & & & 25 months \\
\hline & & & & & & & & & & AWD \\
\hline Male & 18 & SCC, G3 & Uncontrolled & CRT & $S+R T$ & $\mathrm{SP}+\mathrm{ND}$ & superficial & $<3 \mathrm{~cm}$ & - & M \\
\hline & & & & & & & & & & DOD \\
\hline & & & & & & & & & & 65 months \\
\hline Male & 56 & SCC, G3 & Delayed & CRT & $S+R T$ & $\mathrm{SP}+\mathrm{ND}$ & inferior & $>3 \mathrm{~cm}$ & - & LR \\
\hline & & & 60 months & & & & superficial & & & DOD \\
\hline & & & & & & & & & & 11 months \\
\hline Male & 57 & $\mathrm{SCC}, \mathrm{G} 3$ & Delayed & CRT & $S+R T$ & $T P+N D$ & inferior & $>3 \mathrm{~cm}$ & - & DOD \\
\hline & & & 23 months & & & & superficial & & & 13 months \\
\hline Male & 52 & SCC, G3 & Delayed & RT & $S+C R T$ & $\mathrm{SP}+\mathrm{ND}$ & superficial & $<3 \mathrm{~cm}$ & - & DOD \\
\hline & & & $65 \mathrm{~m}$ & & & & & & & 34 months \\
\hline Male & 67 & SCC, G3 & Delayed & RT & $S+C R T$ & $T P+N D$ & superficial & $>3 \mathrm{~cm}$ & + & LR \\
\hline & & & ns & & & & & & & ANED \\
\hline & & & & & & & & & & 120 months \\
\hline male & 61 & SCC, G3 & Delayed & CRT & $\mathrm{S}+\mathrm{CRT}$ & $T P+N D$ & superficial & $>3 \mathrm{~cm}$ & + & M \\
\hline & & & 22 & & & & & & & DOD \\
\hline
\end{tabular}

17 months 
nodes, plus a 3 to $5 \mathrm{~mm}$ margin. Treatment was delivered by a stationary, multileaf intensity-modulating collimator (Varian, Palo Alto, California, United States). All targets were treated simultaneously using the simultaneous integrated boost technique.

Patients were considered eligible for the radiation treatment if they had histologically confirmed NPC with metastasis to parotid lymph nodes, including the uncontrolled disease (indicating that residual tumors remain after IMRT) and delayed metastasis. Patients with primary parotid malignancies, lymphomas, history of a second primary tumor, direct tumor extension to the parotid gland or advanced untreatable disease were excluded from this study.

A total of 14 patients met the study criteria and their data such as the age, gender, histopathology, clinical findings, and treatment outcome were analyzed. The mean and median follow-up period after treatment of metastatic disease was 55.5 and 34.0 months, respectively (range: 11 to 120 months). Survival analysis was performed using the Kaplan-Meier method.

\section{Results}

The characteristics of the 14 patients were shown in Table 1 . The patients included 12 male and two female. Age ranged from 18 to 74 years (mean: 50.4 years). The pathological diagnosis of the primary tumors was grade 3 (poorly differentiated carcinoma) in most of the patients. A total of three patients were identified as uncontrolled disease of parotid metastasis because lesions recurred within three months after the initial treatment of radiotherapy. Among the delayed metastasis of parotid group, the mean time interval between the treatment of the primary tumor and the diagnosis of metastatic disease to the parotid gland was 55.9 months (range: 15 to 108 months). All patients presented with a clinically palpable parotid metastatic mass on physical examination. A total of six patients (42.9\%) had additional enlarged cervical lymph nodes. The most common location of metastases within the parotid gland was the inferior or superficial parotid nodes, and four patients had positive nodes in both the superficial and deep parotid nodes.

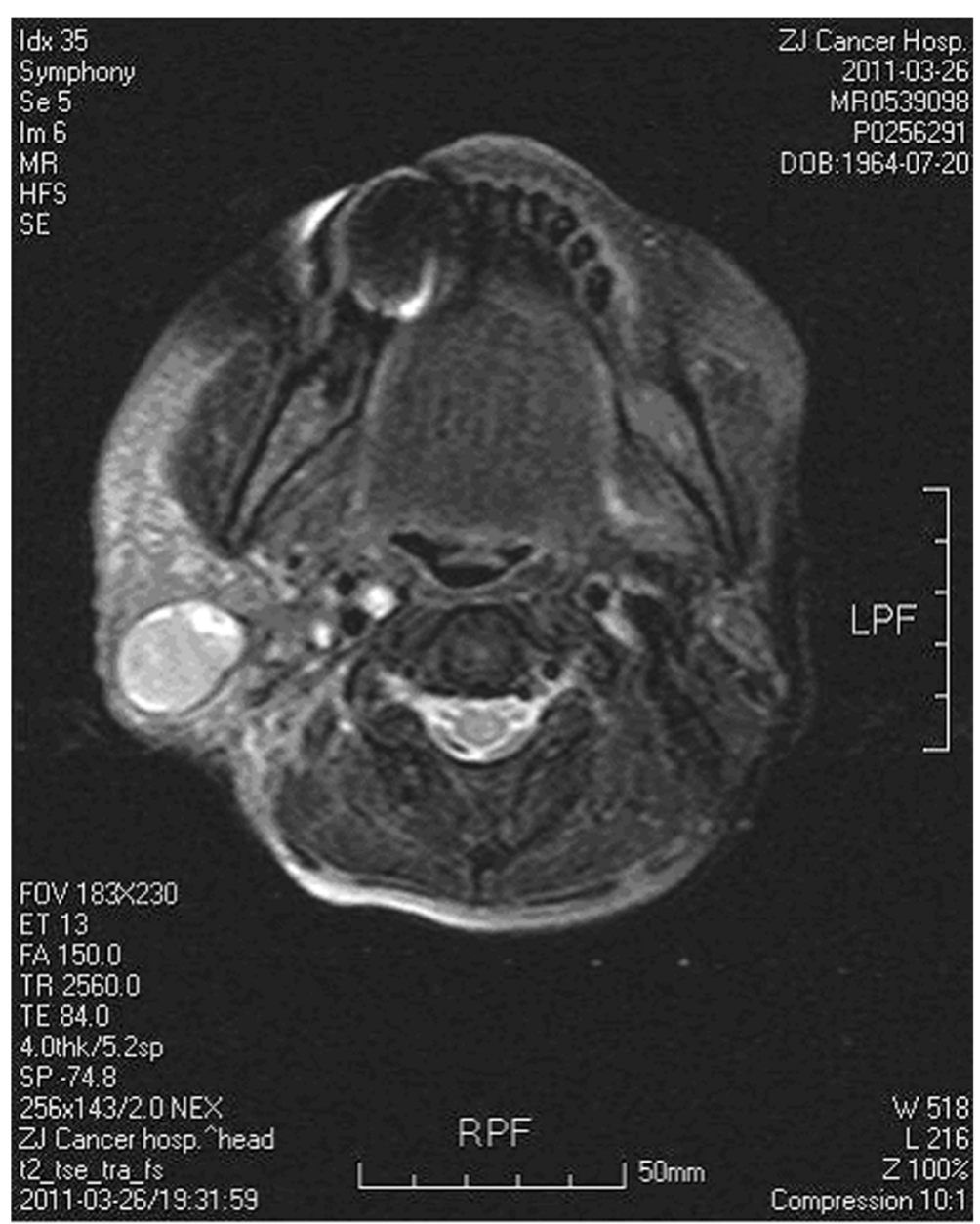

Figure $1 \mathrm{MRI}$ image of uncontrolled parotid metastasis of nasopharyngeal carcinoma after radiotherapy. Multiple swollen lymph nodes were observed in bilateral carotid sheath and pharyngeal lymph node area. 
All 14 patients received IMRT and/or chemotherapy as their initial treatment. Magnetic resonance imaging (MRI) confirmed uncontrolled parotid metastasis parotid metastasis in three patients and the typical MRI image for one patient is shown in Figure 1.

For the other 11 patients, MRI imaging confirmed delayed parotid metastasis and the typical MRI image for one patient is shown in Figure 2. Among the 11 patients presenting with delayed parotid metastasis, three cases underwent surgery and adjuvant radiotherapy, three cases underwent surgery, adjuvant radiotherapy, and/or chemotherapy, and five cases underwent surgery alone. The surgery procedure for the treatment of parotid metastasis was as follows: total parotidectomy with neck dissection, superficial parotidectomy with neck dissection, partial parotidectomy with neck dissection, total parotidectomy, and superficial parotidectomy.

Postoperative complications included facial paralysis or partial facial paralysis, parotid fistula, and flap necrosis. At the last follow-up assessment after treatment of parotid lymph nodes, tumor recurrence occurred in three patients and five patients showed distant metastasis. A total of eight patients died of disease, three patients were alive with no evidence of disease, and three patients were alive with disease. The overall three- and five-year cumulative survival was $49.5 \%$ and $37.1 \%$, respectively. The medium survival was 34 months (Figure 3).

\section{Discussion}

The incidence of NPC is high in China, especially in the southeast, including the Zhejiang province. Radiotherapy is the main treatment method for NPC and the usual dose of radiotherapy is between 60 and $70 \mathrm{~Gy}$. With the development of IMRT, the protocols for NPC radiotherapy have been improved. To prevent the occurrence of xerostomia, the dose of IMRT is regulated. Normally, the dose for the radiation of parotid gland is limited to V26 to $30<50 \%$. However, for any radiotherapy technique that involves facial and cervical joint field and auriculotemporal field in the facial and cervical regions, the dose for

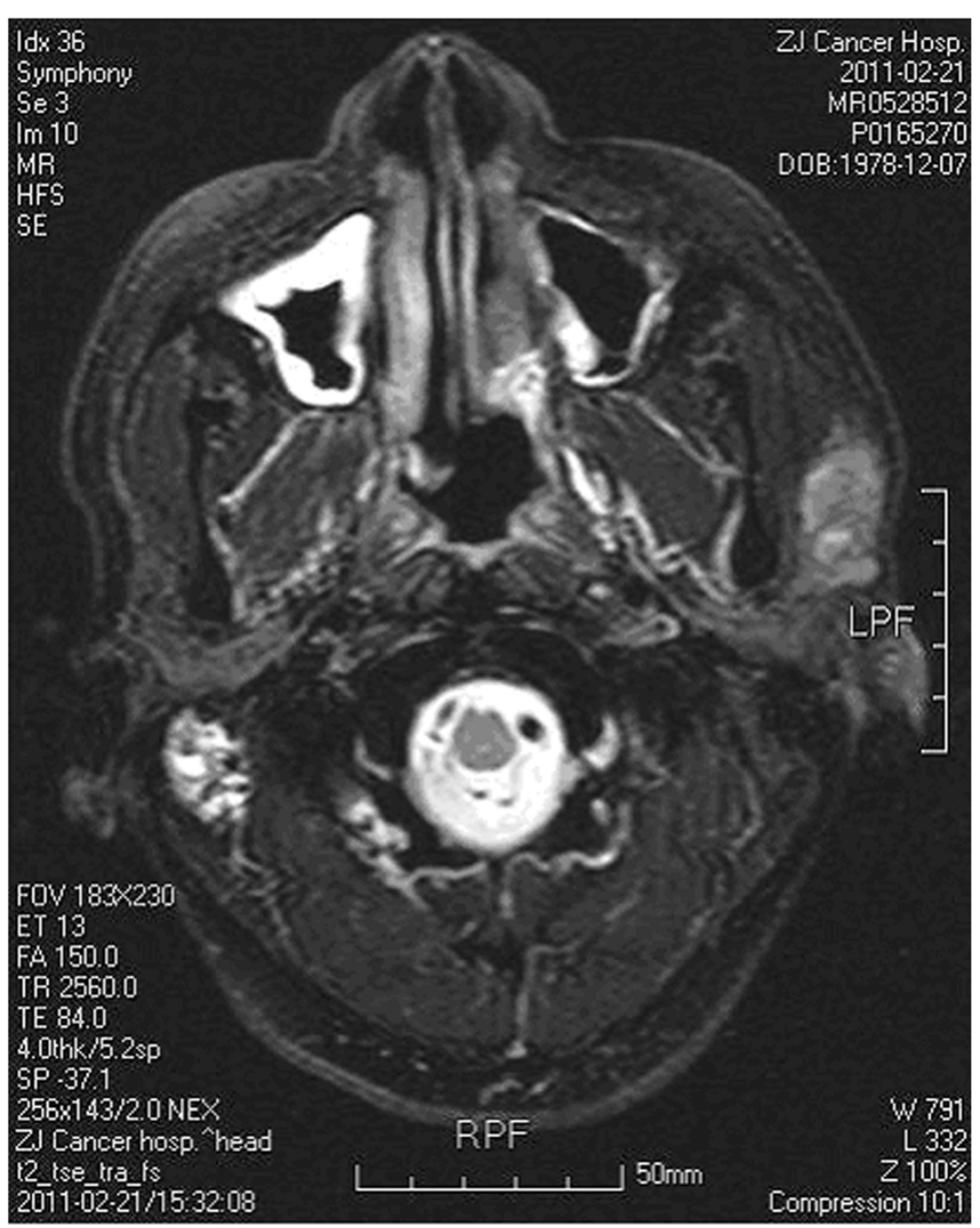

Figure 2 MRI image of delayed parotid metastasis of nasopharyngeal carcinoma after radiotherapy. A nodule about $2.4 \times 1.4 \mathrm{~cm}$ was observed in the left parotid gland. 


\section{Survival Function}

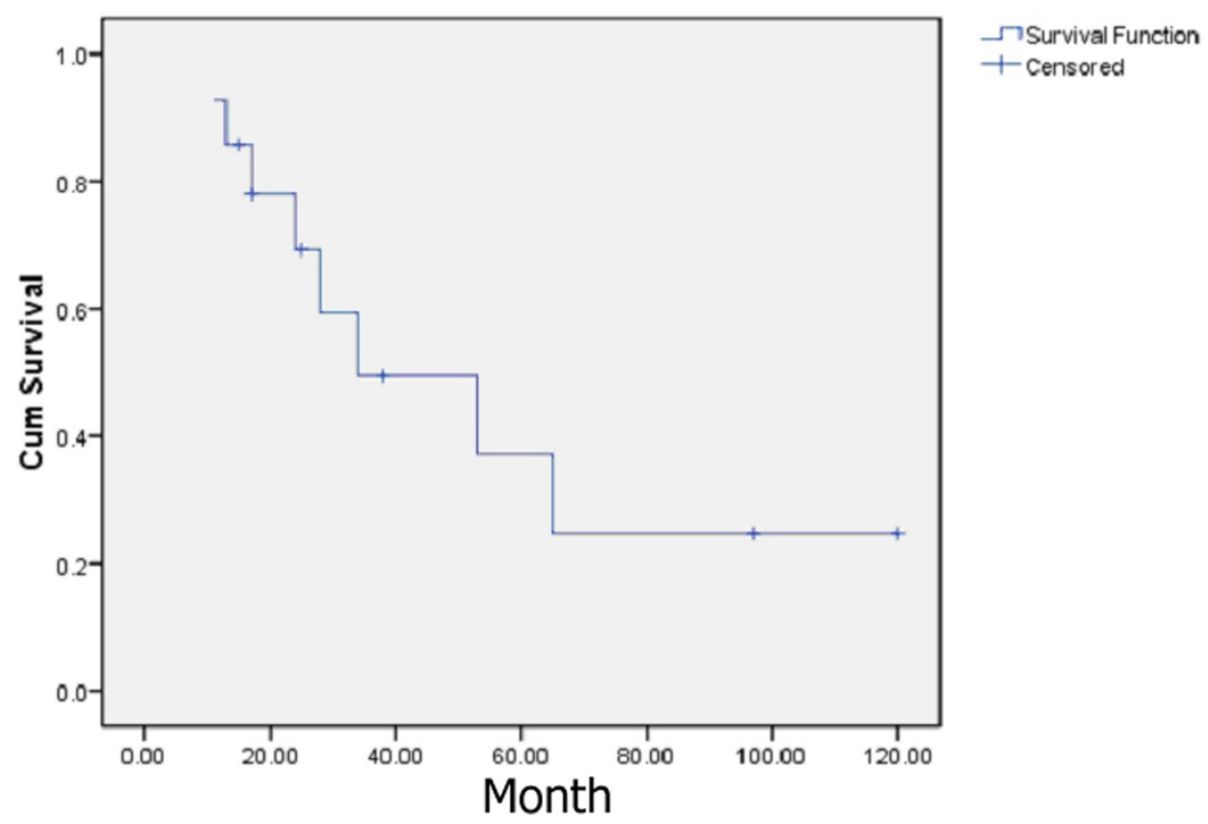

Figure 3 Kaplan-Meier curve estimating the post-operative overall survival of 14 patients presenting with metastasis of nasopharyngeal carcinoma to parotid lymph nodes.

radiation of the parotid gland is higher than that in IMRT. This may explain why the incidence of NPC metastasis to parotid gland has recently increased with the application of IMRT.

The parotid lymphatics are known to receive drainage from a wide region of the head and neck [4,5]. Parotid nodes are divided into superficial and deep groups based on the relation to facial nerve. Lymph nodes are present in superficial and deep lobes of the gland. The superficial and deep lobe has 3.9 to 7.6 and 1.05 to 2.3 lymph nodes, respectively [6,7]. These intraparotid lymphatics render the parotid uniquely susceptible to tumor metastasis [8]. However, pathological findings have shown that all the parotid lymph nodes lie lateral to the retromandibular vein and not the facial nerve, thus any dissection that follows the nerve may leave residual disease because of anatomical variation in the position of the facial vein relative to the nerve [9].

Pathologic findings showed grade 3 tumors in most of the patients. We observed the correlation of increased risk of parotid node involvement with an increased number of cancer-positive cervical lymph nodes, consistent with a previous study [10].

Due to parotid node metastasis, it is important to have a careful clinical and radiographic evaluation of the parotid region in a patient with NPC cancer and cervical metastasis. During neck dissection, careful intraoperative inspection and palpation of the parotid should be performed. We recommend the removal of parotid tail nodes if metastatic involvement is suspected. There is still controversy on the selection of surgery to treat metastasis to parotid lymph nodes; while some surgeons prefer superficial parotidectomy, others prefer total parotidectomy [11]. Facial nerve preservation should be attempted unless the nerve is grossly involved with tumor.

In the present study, amongst the six patients who underwent a total parotidectomy, four were diagnosed with metastasis within the deep lobe. Therefore, we think that total parotidectomy is necessary due to the poor prognosis of untreated deep-lobe metastasis, although it could increase the risk of temporary facial nerve dysfunction.

Metastatic disease to the parotid gland is mostly caused by SCC of the head and neck, and long-term survival remains poor despite combined treatment modalities [12]. Several studies reported positive surgical margins, extranodal spread, advanced tumor stage, and the absence of adjuvant irradiation as factors of poor locoregional control $[13,14]$. Combination therapy with surgery and radiotherapy has been shown to be effective to improve the survival of patients with advanced head and neck cancer $[14,15]$. In terms of timing, surgery is considered the first and best option for patients deemed suitable for that, after a careful pre-operative risk-assessment. In cases of extranodal spread and advanced tumor stage, radiotherapy and/or chemotherapy are needed. 


\section{Conclusions}

The application of IMRT should be taken into account for metastatic disease to the parotid gland. Metastasis to the parotid lymph nodes should be examined in patients with NPC before initial treatment and after IMRT. For patients with substantial cervical metastasis, we recommend the resection of the tail of the parotid gland and the inferior parotid lymph nodes during the neck dissection. If intraparotid lymph node metastases are detected, we recommend total parotidectomy and adjuvant therapy.

\section{Abbreviations}

GTV: gross target volume; IMRT: intensity-modulated radiation therapy; MRI: Magnetic resonance imaging; NPC: nasopharyngeal carcinoma; PGTV: primary gross target volume; PTV: planning target volume; SCC: squamous cell carcinoma.

\section{Competing interests}

The authors declare that they have no competing interests.

\section{Authors' contributions}

MG designed the study. SW and $J$ collected information and prepared the original draft. LG and KW researched the relevant literature SZ and SW revised the manuscript. All authors have read and approved the manuscript.

\section{Acknowledgements}

This study was supported by Zhejiang Provincial Program for the Cultivation of High-level Innovative Health talents(Health Bureau of Zhejiang Province extended 2008-134).

\section{Author details}

${ }^{1}$ Department of Oncology, Second Affiliated Hospital, Zhejiang University School of Medicine, 88\# Jiefang Road, Hangzhou 310009, China. Department of Radiation Oncology, Zhejiang Cancer Hospital, 38\# Guangji Road, Hangzhou 310022, China. ${ }^{3}$ Department of Head and Neck Surgery, Zhejiang Cancer Hospital, 38\# Guangji Road, Hangzhou 310022, China.

Received: 30 August 2014 Accepted: 5 December 2014

Published: 26 January 2015

\section{References}

1. Antonio JK, Santini S, Politi D, Sulfaro S, Spaziante R, Alberti A, et al. Sentinel lymph node biopsy in squamous cell carcinoma of the head and neck: 10 years of experience. Acta Otorhinolaryngol Ital. 2012;32:18-25.

2. Sanders JG, Smith KG, Jameson MB, de Groot C, White J. Persistent neck disease after chemoradiation for head and neck squamous cell carcinoma. J Laryngol Otol. 2012;126:1121-6.

3. Nuyens M, Schüpbach J, Stauffer E, Zbären P. Metastatic disease to the parotid gland. Otolaryngol Head Neck Surg. 2006;135:844-8.

4. Stenner M, Molls C, Luers JC, Beutner D, Klussmann JP, Huettenbrink KB. Occurrence of lymph node metastasis in early-stage parotid gland cancer. Eur Arch Otorhinolaryngol. 2012;269:643-8.

5. Ord RA, Ward-Booth RP, Avery BS. Parotid lymph node metastases from primary intra-oral squamous carcinomas. Int J Oral Maxillofac Surg. 1989;18:104-6.

6. Pisani P, Ramponi A, Pia F. The deep parotid lymph nodes: an anatomical and oncological study. J Laryngol Otol. 1996;110:148-50.

7. Prins-Braam PM, Raaijmakers CP, Terhaard CH. Location of cervical lymph node metastases in oropharyngeal and hypopharyngeal carcinoma: implications for cranial border of elective nodal target volumes. Int J Radiat Oncol Biol Phys. 2004;58:132-8.

8. Olsen SM, Moore EJ, Koch CA, Kasperbauer JL, Olsen KD. Oral cavity and oropharynx squamous cell carcinoma with metastasis to the parotid lymph nodes. Oral Oncol. 2011;47:142-4.

9. Batsakis JG. Parotid gland and its lymph nodes as metastatic sites. Ann Otol Rhinol Laryngol. 1983;92:209-10.

10. Harada H, Omura K. Metastasis of oral cancer to the parotid node. Eur J Surg Oncol. 2009;35:890-4.
11. Garatea-Crelgo J, Gay-Escoda C, Bermejo B, Buenechea-Imaz R. Morphological study of the parotid lymph nodes. J Craniomaxillofac Surg. 1993;21:207-9

12. O'Hara J, Ferlito A, Takes RP, Rinaldo A, Strojan P, Shaha AR, et al. Cutaneous squamous cell carcinoma of the head and neck metastasizing to the parotid gland-a review of current recommendations. Head Neck. 2011;33:1789-95.

13. Khurana VG, Mentis DH, O'Brien CJ, Hurst TL, Stevens GN, Packham NA Parotid and neck metastasis from cutaneous squamous cell carcinoma of the head and neck. Am J Surg. 1995;170:446-50.

14. Chua MS, Veness MJ, Morgan G, Shakespeare T, Hehir A, Gebski V, et al. Parotid lymph node metastasis from cutaneous squamous cell carcinomas: treatment outcome and prognostic factors following surgery and adjuvant radiotherapy. Australas Radiol. 2002;46:174-9.

15. Rudzianskas $V$, Inciura A, Juozaityte $E$, Rudzianskiene $M$, Kubilius $R$, Vaitkus $S$, et al. Reirradiation of recurrent head and neck cancer using high-dose-rate brachytherapy. Acta Otorhinolaryngol Ital. 2012;32:297-303.

doi:10.1186/1477-7819-13-1

Cite this article as: Wang et al:: Metastasis of nasopharyngeal carcinoma to parotid lymph nodes: a retrospective study. World Journal of Surgical Oncology 2015 13:1.

\section{Submit your next manuscript to BioMed Central and take full advantage of:}

- Convenient online submission

- Thorough peer review

- No space constraints or color figure charges

- Immediate publication on acceptance

- Inclusion in PubMed, CAS, Scopus and Google Scholar

- Research which is freely available for redistribution 